\title{
Variasi Nilai Gradien Hidrolik dan Pengaruhnya terhadap Perubahan Nilai Tahanan Jenis pada Sistem Akifer Bersudut Berdasarkan Pendekatan Model Fisik
}

\author{
Budiono $^{1}$, Deny Juanda Puradimaja ${ }^{2}$ \& B. Sulistijo ${ }^{3}$ \\ ${ }^{1}$ Divisi Hidrogeologi - Artesia Global Sarana, PT. (consultan \& trainer) \\ ${ }^{2}$ Departemen Teknik Geologi, FIKTM - ITB \\ ${ }^{3}$ Departemen Teknik Pertambangan, FIKTM - ITB
}

\begin{abstract}
Abstrak. Inti dari penelitian ini adalah simulasi terhadap model fisik akifer tertekan bersudut pada skala laboratorium. Model fisik yang digunakan berbentuk kotak dengan panjang, lebar dan tinggi masing-masing adalah 79,50 $\mathrm{cm} ; 78,00 \mathrm{~cm}$ dan $10,00 \mathrm{~cm}$. Material akifer yang digunakan tersusun oleh pasir kasar bergradasi baik dengan nilai koefisien keseragaman 7,105. Akifer tersebut disimulasikan sebagai akifer tertekan dengan ketebalan $8 \mathrm{~cm}$. Pengukuran model fisik meliputi pengukuran elevation head $(\mathrm{z})$, pressure head $\left(\mathrm{h}_{\mathrm{p}}\right)$, total head $(\mathrm{h})$, dan pengukuran tahanan jenis dengan Metode Schlumberger. Pada awalnya, model akifer tertekan dibuat sebagai lapisan akifer mendatar, sehingga untuk mendapatkan variasi nilai gradien hidrolik dan kemiringan lapisan, kotak model fisik diposisikan dengan berbagai sudut kemiringan: $0^{\circ}, 10^{\circ}, 20^{\circ}$ dan $27^{\circ}$. Untuk mendapatkan hasil yang representatif, digunakan 2 jenis arah bentangan: sejajar strike dan tegak lurus strike.

Kenaikan nilai gradien hidrolik akan menyebabkan kecenderungan menurunnya nilai tahanan jenis sebenarnya $(\rho)$ dari sistem. Berdasarkan arah bentangan pengukuran geolistrik dan nilai $\mathrm{R}^{2}$, maka dari ketiga persamaan yang dihasilkan terpilih 2 persamaan representatif, yaitu: 1). Arah bentangan sejajar strike: $\left.\rho=-4,88 \ln (i)+64,60 ; \mathrm{R}^{2}=0,95.2\right)$. Arah bentangan tegak lurus strike tanpa koreksi terhadap $\mathrm{AB} / 2$ dan nilai $\mathrm{K}: \rho=-3,80 \ln (i)+58,20 ; \mathrm{R}^{2}=0,99$.
\end{abstract}

Kata Kunci: strike, tahanan jenis, gradien hidrolik, model fisik, akifer tertekan. 


\begin{abstract}
The core of this research is simulation on a physical model of inclined confined aquifer in laboratory scale. The model dimensions is $79.50 \mathrm{~cm}$ long, $78.00 \mathrm{~cm}$ wide, and $10.00 \mathrm{~cm}$ tall. The aquifer is simulated as single confined aquifer with thickness of $8 \mathrm{~cm}$. The aquifer material is composed of coarse sand with good gradation and has uniformity coefficient of 7.105. The measurements consist of elevation head ( $\mathrm{z})$, pressure head $\left(\mathrm{h}_{\mathrm{p}}\right)$, total head $(\mathrm{h})$, and resistivity with Schlumberger configuration. The confined aquifer layer is set up to be horizontal. Then, in order to get the hydraulic gradient and dip layer variations, the position of the model box is inclined with varied degree of: $0^{0}, 10^{\circ}, 20^{\circ}$, and $27^{0}$. To get the most representative result, the resistivity is measured with line spread parallel to strike and perpendicular to strike.

The analysis shows that the increase of the hydraulic gradient $(i)$ have the tendency to cause the decrease of true resistivity values $(\rho)$. Based on the line spread direction and $\mathrm{R}^{2}$ values, there are 2 representatives equations as follows: 1). With line spread parallel to strike: $\rho=-4,88 \ln (i)+64,60 ; \mathrm{R}^{2}=0,95$. 2). With line spread perpendicular to strike without correction on $\mathrm{AB} / 2$ and $\mathrm{K}$ value: $\rho=-3,80 \ln (i)+58,20 ; \mathrm{R}^{2}=0,99$.
\end{abstract}

Keywords: Strike, resistivity, hydraulic gradient, physical modelling, confined aquifer.

\title{
$1 \quad$ Pendahuluan
}

Terjadinya aliran airtanah dalam suatu media porus, dikendalikan oleh gradien hidrolik. Jika kemiringan lapisan akifer tersebut bervariasi, maka beberapa parameter energi dalam sistem tersebut akan berubah.

Untuk tujuan kegiatan eksplorasi hidrogeologi, penentuan atau prediksi karakter hidrolik akifer mutlak diperlukan. Ada beberapa metoda yang dapat digunakan untuk tujuan tersebut diantaranya adalah Metoda Geofisika Tahanan Jenis. Metoda ini mengukur sifat fisik lapisan batuan yaitu sifat tahanan jenisnya, dengan cara menginjeksikan arus listrik ke dalam bumi melewati sepasang elektroda arus. Adapun nilai beda potensial yang dihasilkan, diukur melalui sepasang elektroda potensial. Nilai tahanan jenis yang dihasilkan merupakan nilai tahanan semu (apparent resistivity). Nilai tersebut didapatkan dengan cara membagi nilai beda potensial dengan besarnya arus yang diinjeksikan serta dikalikan dengan faktor geometri (K).

Pada umumnya, metoda geolistrik tahan jenis menghasilkan pengukuran yang akurat pada lapisan akifer yang mendatar. Namun untuk pengukuran tahanan jenis pada lapisan akifer bersudut, perlu diteliti pengaruh arah bentangan terhadap strike dan pengaruh variasi nilai gradien hidrolik terhadap nilai tahanan jenis sebenarnya ( $\rho)$. 


\section{$2 \quad$ Pendekatan Dasar Teori}

\subsection{Prinsip Dasar Aliran Airtanah}

Aliran airtanah menghasilkan beberapa energi yaitu energi mekanik, termal, dan kimia. Secara umum proses aliran airtanah tersebut mengikuti Hukum Fisika dan Termodinamika (Fetter, 1988).

Secara fisika, energi mekanik diklasifikasikan menjadi 3 (tiga) tipe energi yaitu: energi kinetik, energi potensial gravitasi, dan energi tekanan fluida (energy of fluid pressure) yang dinyatakan dalam bentuk persamaan Bernoulli:

$$
\begin{aligned}
& E_{t b}=\frac{1}{2 g} v^{2}+z+\frac{P}{\rho g} \\
& \mathrm{E}_{t m}=\frac{1}{2} v^{2}+g z+\frac{P}{\rho}
\end{aligned}
$$

dimana :

$\rho=$ densitas (massa/volume), kg.m ${ }^{-3}$

$\mathrm{g}=$ percepatan gravitasi $\left(9,8 \mathrm{~m} \cdot \mathrm{dt}^{-2}\right)$

$\mathrm{Z}=$ posisi massa fluida dari datum, $\mathrm{m}$

$\mathrm{P}=$ pressure (F/A), Pascal atau N.m ${ }^{-2}$ atau N-m.m $\mathrm{m}^{-3}$

$\mathrm{v}=$ kecepatan aliran, $\mathrm{m} \cdot \mathrm{dt}^{-1}$

$\mathrm{E}_{\mathrm{tb}}=$ total energi per satuan berat, $\mathrm{m}$

$\mathrm{E}_{\mathrm{tm}}=$ total energi per satuan massa, ${\mathrm{J} . \mathrm{kg}^{-1}}^{-1}$.

\subsection{Gaya Potensial (Force Potential) dan Tinggi Tekan Hidrolik} (Hydraulic Head)

Untuk mempermudah analogi, komponen gaya dalam aliran airtanah diperlihatkan pada Gambar 1, dengan persamaan masing-masing gaya adalah sebagai berikut:

$$
P=\rho g h_{p}, h=z+\frac{P}{\rho g} .
$$

Apabila total energi potensial disebut sebagai gaya potensial (force potential) dan dinotasikan sebagai phi $(\phi)$, maka persamaan Bernoulli di atas dapat ditulis menjadi persamaan berikut:

$$
\begin{aligned}
& \phi=g z+\frac{P}{\rho}=g z+\frac{\rho g h_{p}}{\rho}=g\left(z+h_{p}\right) \\
& \phi=g h
\end{aligned}
$$


Sejumlah energi potensial yang hilang karena gesekan, berubah menjadi bentuk energi panas yang relatif rendah (a lower form of energy). Selanjutnya, selama airtanah mengalir dalam akifer akan terjadi kenaikan temperatur di dalam sistem, yaitu energi mekanik akan berubah menjadi energi panas (thermal energy), sehingga persamaan aliran air menjadi berikut ini (persamaan oleh Streeter et al, 1988):

$$
\frac{1}{2 g} v_{1}^{2}+z_{1}+\frac{P_{1}}{\rho g}=\frac{1}{2 g} v_{2}^{2}+z_{2}+\frac{\mathrm{P}_{2}}{\rho g}+\begin{aligned}
& \text { kehilangan } \\
& \text { energi }
\end{aligned}
$$

\subsection{Sifat Konduktif Akifer}

Nilai tahanan jenis suatu lapisan batuan penyusun akifer ditentukan oleh jumlah kandungan air, salinitas air, dan sifat fisik batuan. Lapisan akifer yang mengandung air dapat dianalogikan sebagai lapisan yang mengandung elektrolit.

Ketika medan listrik dialirkan ke dalam suatu larutan elektrolit, maka jumlah arus yang mengalir merupakan hasil kali dari jumlah ion dengan nilai kecepatan pergerakan ion tersebut. Jika 1 (satu) gram garam dalam suatu larutan yang berisi muatan 96.500 coulombs (konstanta Faraday, F), maka arus yang mengalir melewati larutan elektrolit per 1 (satu) volt per 1 (satu) meter dapat dinyatakan dengan persamaan berikut (Keller, 1966):

$$
\mathrm{I}=\mathrm{A} F\left(c_{1} v_{1}+c_{2} v_{2}+c_{3} v_{3} \ldots \ldots+c_{n} v_{n}\right)
$$

keterangan :

$\mathrm{c}_{\mathrm{n}} \quad=$ nilai konsentrasi ion (mol)

$\mathrm{v}_{\mathrm{n}}=$ mobilitas ion $\left(\mathrm{m}^{2} \mathrm{dt}^{-1}\right.$ Volt $\left.^{-1}\right)$

$\mathrm{A}=$ luas area yang dilewati arus, $\mathrm{m}^{2}$

$\mathrm{F}=$ konstanta Faraday, $9,648 \times 10^{4}$ Coulomb. $\mathrm{mol}^{-1}$

$\mathrm{I} \quad=$ arus yang mengalir, Ampere

Selanjutnya, nilai tahanan jenis dari larutan dapat didefinisikan atau dianalogikan sebagai arus yang melewati suatu bidang dengan luas $1 \mathrm{~m}^{2}$, pada beda potensial sebesar 1 Volt $/ \mathrm{m}$. Jika $\rho$ adalah nilai tahanan jenis (ohm.m), maka persamaan 6 dapat diubah menjadi persamaan Keller (1966) sebagai berikut:

$$
\begin{aligned}
& \frac{I}{A}=F\left(c_{1} m_{1}+c_{2} m_{2}+c_{3} m_{3} \ldots \ldots . .\right) \\
& \frac{1}{\rho}=F\left(c_{1} m_{1}+c_{2} m_{2}+c_{3} m_{3} \ldots \ldots . .\right)
\end{aligned}
$$

$\mathrm{m}=$ mobilitas ion $\left(\mathrm{m}^{2} \mathrm{dt}^{-1} \operatorname{Volt}^{-1}\right)$ 


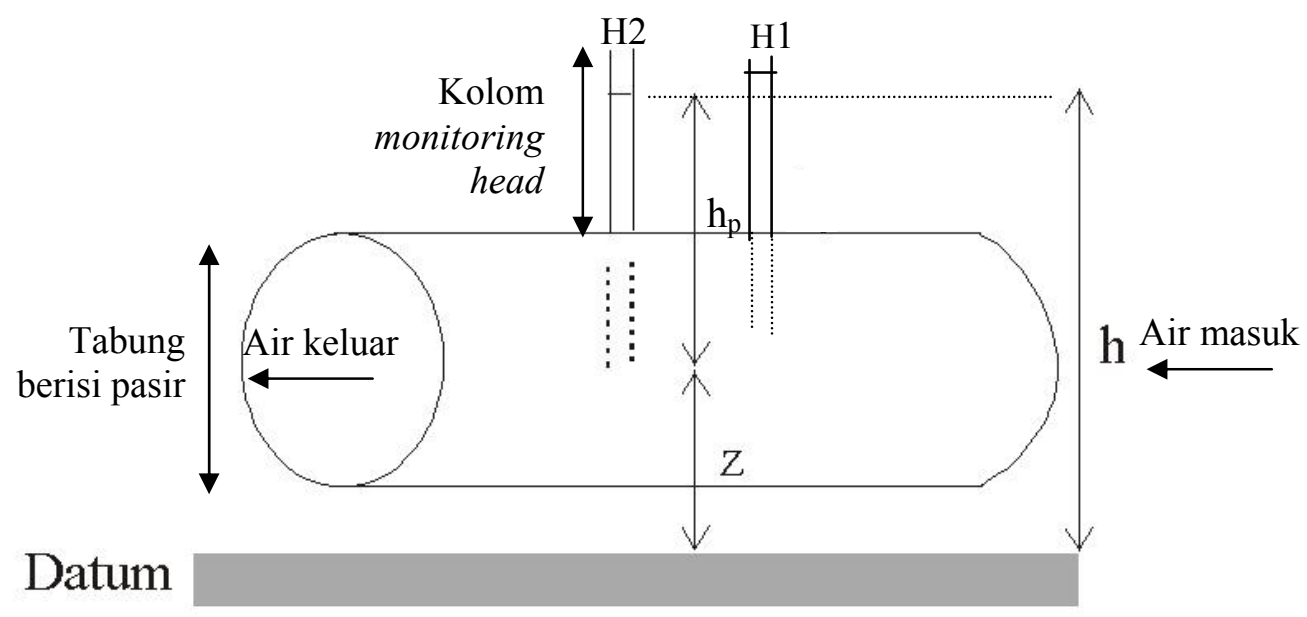

Gambar 1 Gambaran komponen total head $(h)$, elevation head $(z)$, dan pressure head $\left(h_{p}\right)$, pada suatu sistem aliran air yang dilewatkan dalam tabung berisi pasir. Pasir tersebut disimulasikan sebagai akifer tertekan (Fetter, 1988).

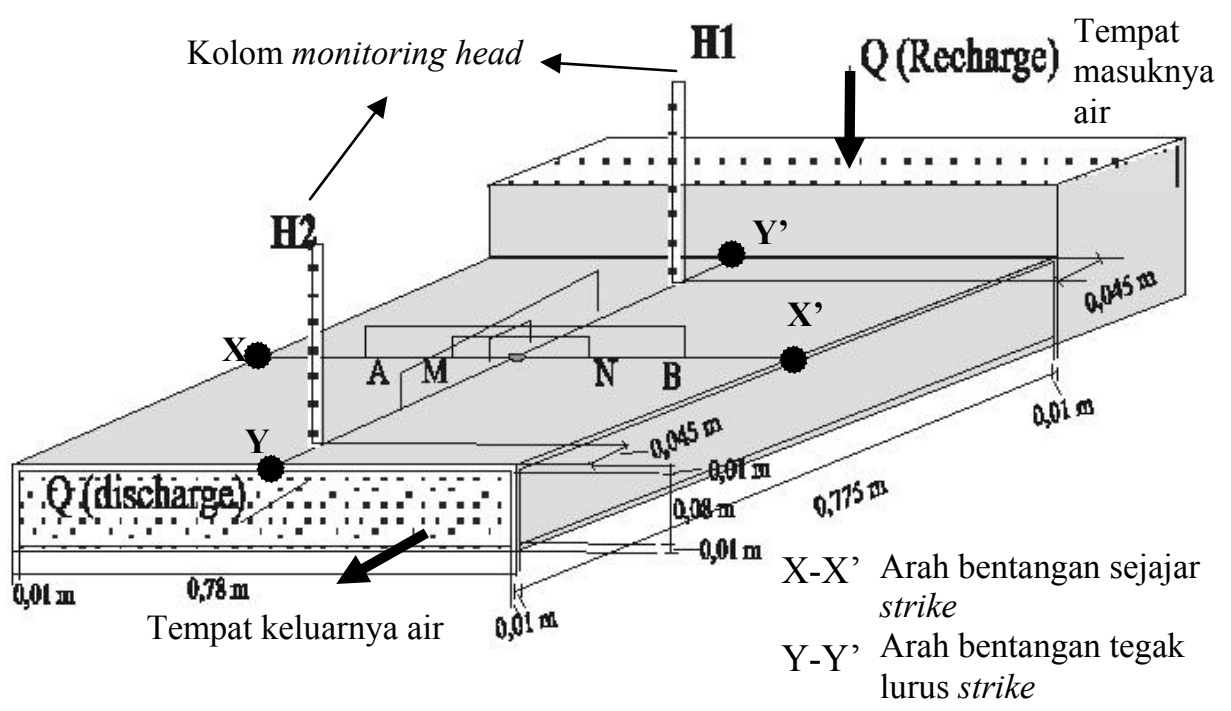

Gambar 2 Bentuk dan dimensi model fisik. 


\section{$3 \quad$ Metoda}

Metoda yang digunakan dalam penelitian ini adalah pengukuran nilai tahanan jenis pada akifer tertekan dengan skala model fisik di laboratorium. Model fisik yang dibuat berbentuk kotak dengan panjang, lebar dan tinggi masing-masing adalah 79,50 cm; 78,00 cm dan 10,00 cm (Gambar 2). Material akifer yang digunakan yaitu pasir kasar bergradasi baik dengan nilai koefisien keseragaman 7,105. Akifer tersebut disimulasikan sebagai akifer tertekan dengan ketebalan 8 $\mathrm{cm}$.

Material akifer dialiri air secara kontinyu dari bagian yang diberi tanda "Q" (recharge). Air kemudian mengalir melalui akifer tertekan dan selanjutnya keluar melalui bagian yang ditandai dengan huruf "Q" (discharge). Pada saat akifer jenuh dengan air secara menyeluruh, pengukuran resistivitas dilakukan pada lintasan $\mathrm{X}-\mathrm{X}^{\prime}$ dan $\mathrm{Y}-\mathrm{Y}^{\prime}$. Jenis pengukuran lain, yaitu pengukuran ketinggian head, dilakukan melalui kolom monitor $\mathrm{H} 1$ dan $\mathrm{H} 2$.

Untuk mendapatkan variasi nilai gradien hidrolik, model fisik diposisikan dengan berbagai sudut kemiringan $0^{\circ}, 10^{\circ}, 20^{\circ}$ dan $27^{\circ}$ (Gambar 3). Pengukuran model fisik meliputi pengukuran elevation head $(\mathrm{z})$, pressure head $\left(\mathrm{h}_{\mathrm{p}}\right)$, total head (h), dan pengukuran tahanan jenis dengan Metode Schlumberger (Gambar 4).

Adapun arah bentangan pengukuran adalah searah strike dan tegak lurus strike. Selanjutnya hasil pengukuran dikalkulasi untuk menghasilkan nilai tahanan jenis semu ( $\rho$ ), yang kemudian dikonversi menjadi nilai tahanan jenis sebenarnya $(\rho)$. Khusus untuk arah bentangan tegak lurus strike, dilakukan 2 jenis perhitungan, dengan koreksi dan tanpa koreksi terhadap komponen titik tengah elektroda arus (spasi $\mathrm{AB} / 2$ ) dan faktor geometri (K). Dengan demikian terdapat 3 jenis pengukuran:1).Searah strike; 2).Tegak lurus strike dengan koreksi; 3).Tegak lurus strike tanpa koreksi.

\section{$4 \quad$ Hasil Penelitian}

\subsection{Analisa Hubungan antara Nilai Gradien Hidrolik dengan Nilai Tahanan Jenis Semu (Apparent Resistivity)}

Hasil dari 4 kali pengambilan data untuk ketiga jenis pengukuran geofisika tahanan jenis metoda Schlumberger, menunjukkan bahwa untuk nilai spasi $\mathrm{AB} / 2$ yang sama, terjadi kenaikan nilai gradien hidrolik. Kenaikan nilai gradien hidrolik tersebut, cenderung menghasilkan nilai tahanan semu ( $\rho$ a) yang menurun. Fenomena tersebut dapat diamati dari hasil pengukuran tahanan jenis semu ( $\rho$ a) pada spasi $\mathrm{AB} / 2=0,12$. Korelasi untuk ketiga jenis pengukuran dinyatakan dalam bentuk 3 buah persamaan berikut ini, seperti digambarkan pada Gambar 5: 


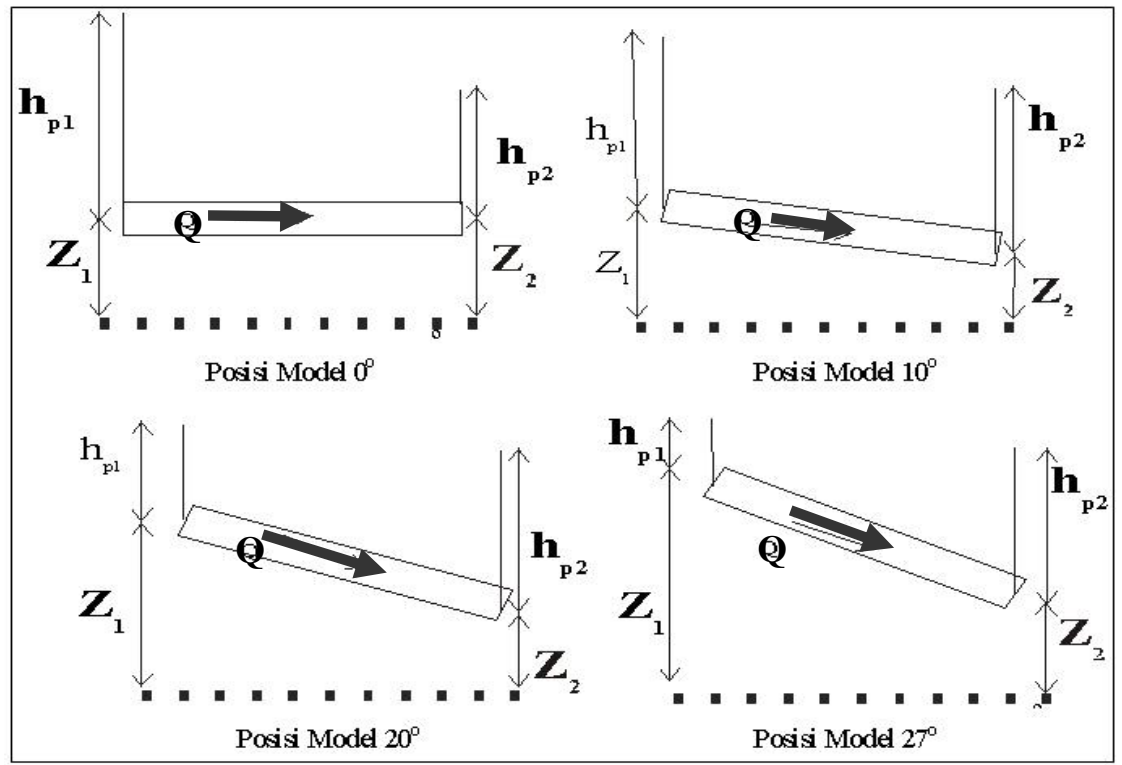

Gambar 3 Variasi kemiringan model fisik untuk mendapatkan variasi nilai gradien hidrolik.

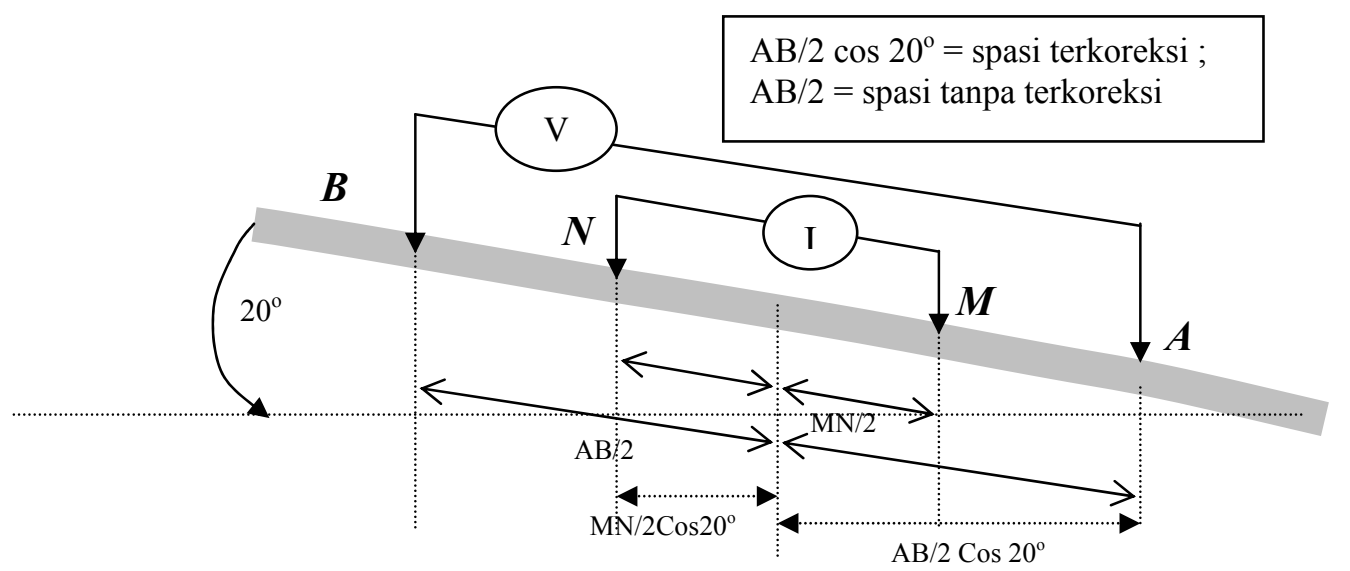

Gambar 4 Konfigurasi pengukuran tahanan jenis pada bidang miring dengan Metode Schlumberger. 


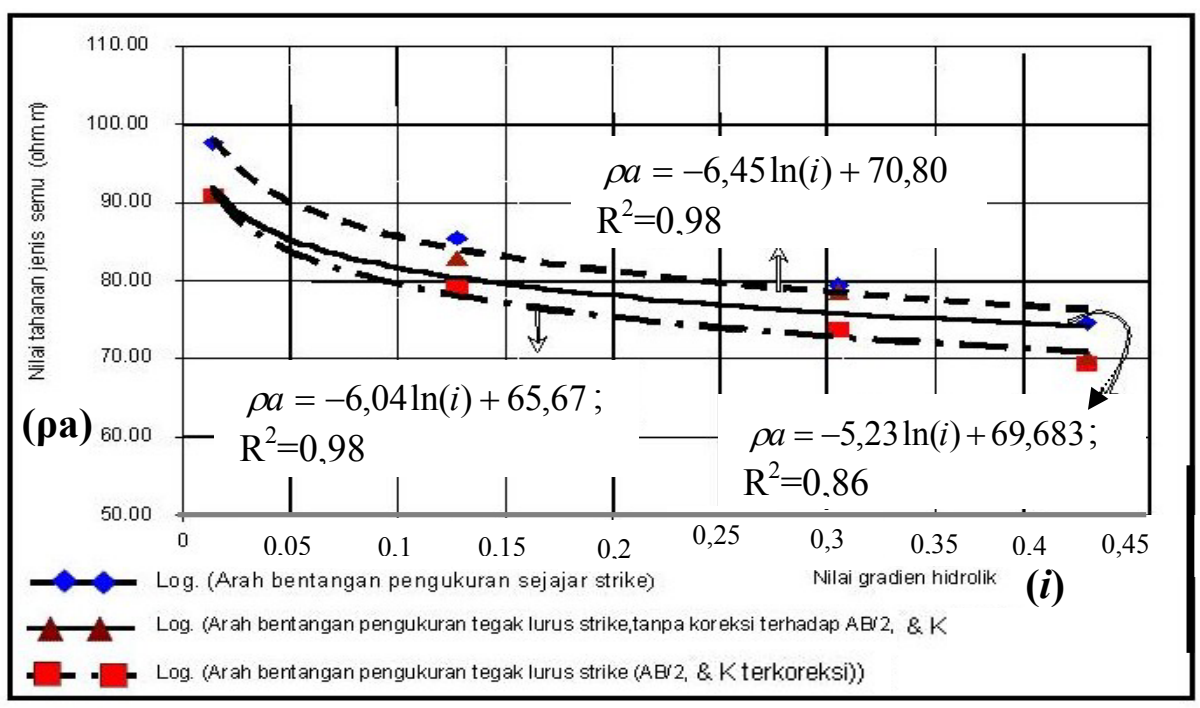

Gambar 5 Variasi hubungan antara nilai gradien hidrolik dengan nilai tahanan jenis semu pada $\mathrm{AB} / 2=0,12$ meter.

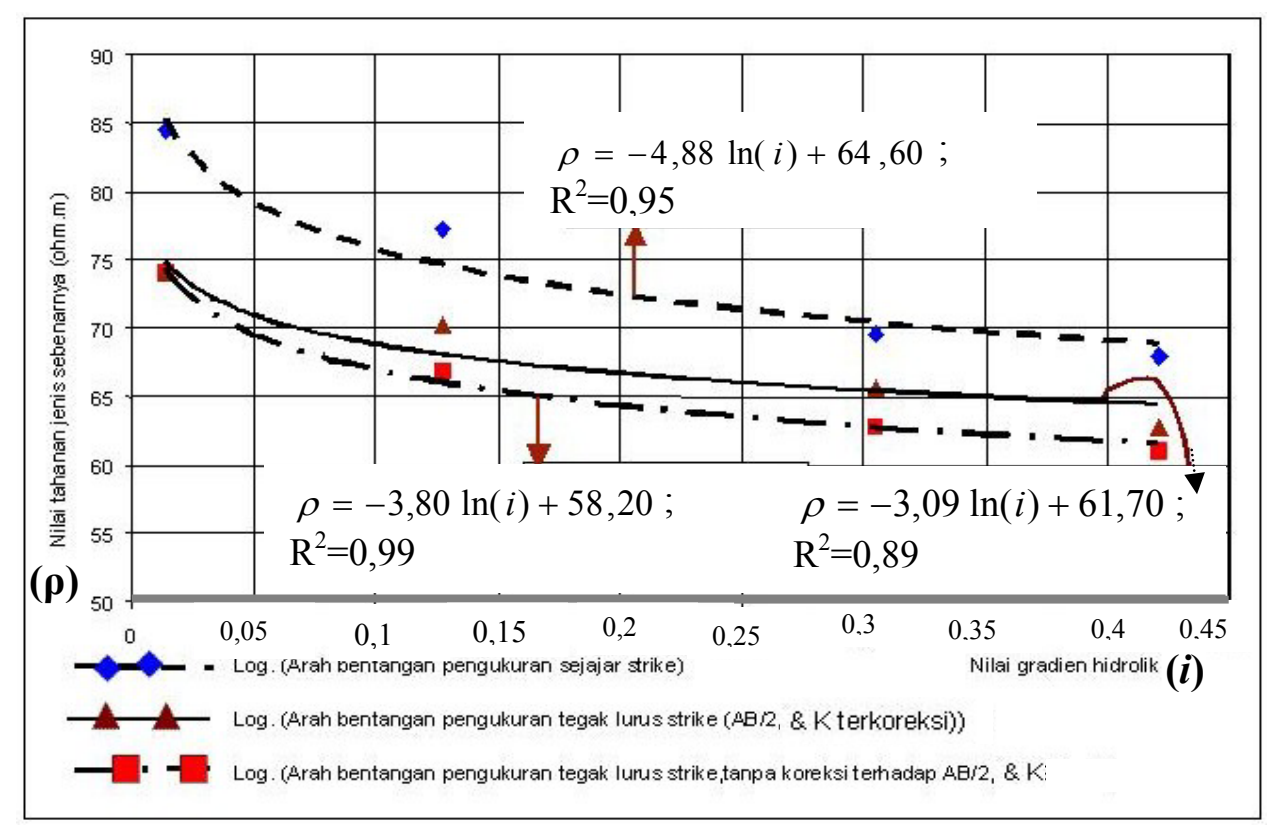

Gambar 6 Variasi hubungan antara nilai gradien hidrolik dengan nilai tahanan jenis sebenarnya pada $\mathrm{AB} / 2=0,12$ meter. 


\section{Pengukuran ke-1.}

Arah bentangan sejajar strike:

$$
\rho a=-6,45 \ln (i)+70,80 ; \mathrm{R}^{2}=0,98 \text {. }
$$

\section{Pengukuran ke-2.}

Arah bentangan tegak lurus strike dengan koreksi terhadap $\mathrm{AB} / 2$ dan $\mathrm{K}$ :

$$
\rho a=-6,04 \ln (i)+65,67 ; \mathrm{R}^{2}=0,98 .
$$

\section{Pengukuran ke-3.}

Arah bentangan tegak lurus strike tanpa koreksi terhadap $\mathrm{AB} / 2$ dan $\mathrm{K}$ :

$$
\rho a=-5,23 \ln (i)+69,68 ; \mathrm{R}^{2}=0,86 \text {. }
$$

\subsection{Analisa Hubungan antara Nilai Gradien Hidrolik dengan Nilai Tahanan Jenis Sebenarnya (True Resistivity)}

Setelah melalui proses konversi dari nilai tahanan jenis semu ( $\rho)$, maka didapatkan nilai tahanan jenis sebenarnya $(\rho)$. Hubungan antara kedua parameter tersebut dapat dinyatakan sebagai berikut (seperti pada Gambar 6):

\section{Pengukuran ke-1.}

Arah bentangan sejajar strike:

$\rho=-4,88 \ln (i)+64,60 ; \mathrm{R}^{2}=0,95$.

\section{Pengukuran ke-2.}

Arah bentangan tegak lurus strike dengan koreksi terhadap $\mathrm{AB} / 2$ dan $\mathrm{K}$ :

$\rho=-3,09 \ln (i)+61,70 ; \mathrm{R}^{2}=0,89$.

\section{Pengukuran ke-3.}

Arah bentangan tegak lurus strike tanpa koreksi terhadap $\mathrm{AB} / 2$ dan $\mathrm{K}$ :

$\rho=-3,80 \ln (i)+58,20 ; \mathrm{R}^{2}=0,99$.

Berdasarkan nilai $\mathrm{R}^{2}$, maka dari ketiga persamaan yang dihasilkan terpilih 2 persamaan representatif, yaitu persamaan hasil pengukuran ke-1 dan ke-3.

\section{$5 \quad$ Kesimpulan}

- Dalam sistem aliran airtanah pada akifer tertekan bersudut, kenaikan nilai gradien hidrolik menyebabkan turunnya nilai tahanan jenis sebenarnya $(\rho)$.

- Untuk kondisi lapisan akifer tertekan bersudut, arah bentangan pengukuran geolistrik dengan metoda Schlumberger yang direkomendasikan adalah:

1) arah bentangan sejajar dengan strike atau

2) arah bentangan tegak lurus terhadap strike tanpa koreksi pada jarak $\mathrm{AB} / 2$ dan nilai $\mathrm{K}$ (faktor geometri). 


\section{Ucapan Terimakasih}

Penulis mengucapkan terima kasih kepada Laboratorium Teknik Eksplorasi, Departemen Teknik Pertambangan ITB, yang telah membiayai penelitian ini melalui Dana Hibah Tim IV (URGE Project).

\section{Daftar Pustaka}

1. Fetter, Applied Hydrogeology, $2^{\text {nd }}$ Ed, University of Wisconsin-Osjkhosh (1988).

2. $\quad$ Streeter et al., Fluid Mechanics, University of Michigan (1988).

3. Keller, George V. \& Frank C. Frischknecht, Electrical Methods in Geophysical Prospecting, Colorado School of Mine (1966). 